\title{
IMPROVEMENT OF THE OPERATIONAL PERFORMANCE OF SRF CAVITIES VIA IN SITU HELIUM PROCESSING AND
} WAVEGUIDE VACUUM PROCESSING DOE/ER/40150--1/42

\author{
C. E. Reece, M. Drury, M. G. Rao, and V. Nguyen-Tuong \\ Thomas Jefferson National Accelerator Facility \\ 12000 Jefferson Avenue, Newport News, VA, 23602 USA
}

\begin{abstract}
The useful performance range of the superconducting if (SRF) cavities in the CEBAF accelerator at Jefferson Lab is frequently limited by electron field emission and derived phenomena. Improvements are required to support future operation of the accelerator at higher than $5 \mathrm{GeV}$. Twelve operational cryomodules have been successfully processed to higher useful operating gradients via rf-helium processing. Progress against field emission was evidenced by improved high-field $Q$, reduced $\mathrm{x}$-ray production and greatly reduced incidence of arcing at the cold ceramic window. There was no difficulty reestablishing beamline vacuum following the processing. Cavities previously limited to $4-6 \mathrm{MV} / \mathrm{m}$ are now operating stably at $6-9 \mathrm{MV} / \mathrm{m}$. By applying a pulsed-rf processing technique, we have also improved the pressure stability of the thermal transition region of the input waveguide for several cavities. [1]
\end{abstract}

\section{INTRODUCTION}

The CEBAF accelerator at Jefferson Lab was designed and constructed to provide $200 \mu \mathrm{A}, 4 \mathrm{GeV} \mathrm{CW}$ electron beams for physics research. Some portions of the acceleration system significantly exceeded the specifications and provide a good basis for extending the energy reach of the machine.[2] In addition, we have begun exploring means of obtaining incremental performance gains via in situ processing techniques. We intend to exhaust the opportunities for such gains as a first step toward significant upgrades of the machine into the $6-8 \mathrm{GeV}$ region.

The 330 SRF cavities in CEBAF are individually powered by $5 \mathrm{~kW}$ klystrons. The principal limitation of the installed cavities is electron field emission and associated phenomena, such as $\mathrm{x}$-ray production, charging and arcing at the cold ceramic of window, and anomalous $2 \mathrm{~K}$ heat load. In addition, some cavities are constrained by the stability of the vacuum in the region between the $2 \mathrm{~K}$ and $300 \mathrm{~K}$ rf windows. Present capabilities project to possible operation of CEBAF at $5.5 \mathrm{GeV}$.

\section{I Motivation}

Based on progress to date, it appears a reasonable goal to make $6.0 \mathrm{GeV}$ operation possible using existing cryomodules by gaining the additional $10 \%$ through in situ processing. If achieved, this would be the most economical route to $6.0 \mathrm{GeV}$.

As CEBAF has entered the mode of sustained beam delivery for physics experiments, opportunities for in situ processing are infrequent. Thus, we pursue effe methods which minimize the preclusion of beam operations and dove-tail with regular machine maintenance.

\subsection{Background}

Helium processing of SRF cavities has been an established technique for many years, even though the exact mechanism by which it effects change remains unclear.[3] It is used to reduce electron field emission in a cavity. Helium is admitted inside the cavity to a pressure just below that suitable for rf discharge, and the cavity is operated at high stored energy with active field emission. Typically, a gradual weakening of the field emission is observed, although processing by events have been reported. It has been variously suggested that the $\mathrm{FE}$ current locally ionizes the helium gas, forming a local plasma which heats and melts the emission source, provides microscopically directed helium ion bombardment of the source, or enhances the local field to the point of drawing out current densities sufficient to explode the emitter.[4]

\subsection{Cavity limitations}

The CEBAF cavities, though performing substantially better than initial specifications, are predominately limited in performance by field emission. Arcs at the cold ceramic rf window are strongly correlated with field emission in the associated cavity. Though some uncertainty remains, the arcs are understood as the discharge of charge accumulated on the ceramic due to either a shower of secondary electrons produced by impingement of primary $\mathrm{FE}$ electrons on the waveguide/beampipe region and/or photoelectric charging by low-energy $\mathrm{x}$-rays.[5] The extremely high bulk resistivity of the $2 \mathrm{~K}$ ceramic produces long relaxation times, with the result that different cavities can be made to arc with periods that range from a few minutes to several hours, depending upon at what operating gradient they are set. Of the $330 \mathrm{SRF}$ cavities, 153 are now limited in usable gradient by this arcing phenomenon.

\section{METHODS}

\subsection{Instrumentation}

To accomplish the processing in the CEBAF tunnel, helium gas was supplied to a cryomodule through a port in a beamline ion pump. The attached manifold provided a turbomolecular pump and an RGA. A fixed volume of $\sim 0.5 \mathrm{~L}$ was precharged with high-purity helium and connected to the manifold through a 0.2 micron particle filter and a remotely 


\section{DISCLAIMER}

This report was prepared as an account of work sponsored by an agency of the United States Government. Neither the United States Government nor any agency thereof, nor any of their employees, make any warranty, express or implied, or assumes any legal liability or responsibility for the accuracy, completeness, or usefulness of any information, apparatus, product, or process disclosed, or represents that its use would not infringe privately owned rights. Reference herein to any specific commercial product, process, or service by trade name, trademark, manufacturer, or otherwise does not necessarily constitute or imply its endorsement, recommendation, or favoring by the United States Government or any agency thereof. The views and opinions of authors expressed herein do not necessarily state or reflect those of the United States Government or any agency thereof. 


\section{DISCLAMMER}

Portions of this document may be illegible in electronic image products. Images are produced from the best available original document. 
controlled needle valve. The quantity of helium admitted was measured by the reduction of pressure in the reservoir volume (typically -5 standard torr-liters).

Ten cryomodules were processed in pairs supplied with helium from the warm girder between them. The beamline gate valves bracketing the cryomodule(s) to be processed were closed for the duration of the activity.

$\mathrm{Rf}$ drive for the klystron was provided by a VCO phaselocked-loop (PLL) rather than the standard CEBAF fixedfrequency if controller. Standard system interlocks, except for beamline vacuum, were required to provide a permissive to the VCO system output.

\subsection{Radiation measurements}

The best indicator of progress against field emission is an increased $Q_{0}$ at high gradient. Unfortunately, measurements of $Q_{0}$ on the cavities in CEBAF implies time-consuming calorimetric methods incompatible with beam operations. With very limited amount of time available for processing activities, we chose to use the $x$-radiation produced by a cavity as its signature of field emission.

Six Geiger-Müller tubes were placed around the cryomodule under test, one between each pair of $\mathrm{rf}$ warm windows and one on the beamline at each end of the module. The response of the G-M tubes was measured for each cavity, both before and after processing.

For the first cryomodule processed, we took the time to measure $Q_{0}$ before and after processing. These data correlated well with the radiation measurements.

\section{$2.3 R F$ controls for processing}

In the interest of enabling parallel processing, we attempted to develop a scheme for He processing using the standard if control system. This proved unsuccessful. The CEBAF SRF cavity geometry is such that there exist, somewhere in the structure, conditions suitable for a multipacting (MP) barrier at a stored energy corresponding to $E_{\text {acc }} \sim 0.7 \mathrm{MV} / \mathrm{m}$.

Although this barrier was occasionally observed in vertical testing during construction, it always processed away and has presented no operational problems. With the introduction of helium into the cavities, however, the situation changed. With only a few exceptions, the barrier was always present and when present, never processed. The helium effectively amplified the secondary electron yield, producing a hard barrier. The multi-bandwidth reactive tuning produced by the multipacting process made fixedfrequency operation impossible.

Although the MP barrier was encountered while using the VCO systems, we developed a technique which routinely bypassed the barrier so that helium-rf processing could proceed at high gradients. Noting that the MP always shifted the frequency higher, we found that if one detuned the VCO high, and slowly approached the upper limit of the capture range of the PLL, one could immediately bypass the MP barrier. The need to use a VCO PLL has thus far limited us to processing only two cavities at a time.

\subsection{Thermal cycle}

A critical part of applying in situ helium processing is fully removing the supplied helium from the beamline to support beam operations. For this purpose, we have found that a warmup to $20 \mathrm{~K}$ is quite adequate for removal of the helium. Limiting the warmup to this range allows us to avoid mechanical stresses and also minimize the total time required.

Following the completion of the helium processing, the inlet JT valve of each cryomodule was closed and $140-250 \mathrm{~W}$ supplied through resistive heaters. The valve to the low pressure ( 40 mbar) return header remained fully open. This heat reduced the $2 \mathrm{~K}$ liquid helium level to $-5 \%$ in $6-10$ hours. The balance of the helium was boiled off with $60 \mathrm{~W}$ and the helium vessel and cavities warmed to $-20 \mathrm{~K}$, as measured by diode thermometers mounted on the cavity assemblies.

During this warmup the turbopump was allowed to pump on the beamline to remove the helium, and also whatever hydrogen was liberated. After a dwell time of approximately 1 hour at $20 \mathrm{~K}$, with beamline pressure now in the $10^{-8}$ torr range, refill of the module began. Typically, a module refilled in 6-10 hours, at which time it was ready for if testing. In one case, the cavities were tuned up and immediately applied to beam operations, with postprocessing characterization deferred for several days.

\section{GAS DYNAMICS}

We established the target He pressure to be $4 \times 10^{-4}$ torr as measured by an RGA at ambient temperature. Equilibration times for $2 \mathrm{~K}$ helium at these pressures was observed to be at least several hours. Operation of the if during the addition of the helium seemed to speed gas migration to the far end of the cryomodule.

Each of the 90 cavities processed was operated at elevated field levels for 20-60 minutes. Frequently, the applied of power was limited by instabilities in the vacuum between the cold and warm of windows. After the $20 \mathrm{~K}$ warmup, we noticed improved stability of this vacuum, which prompts us to plan future helium processing efforts to include both a before and after cryocycle.

There were no difficulties reestablishing beamline vacuum due to residual helium. In a few instances, there was a slow recovery of the hydrogen partial pressure in the $10^{-9}$ torr range that caused some concern. A similar response was observed following a thermal excursion of the $50 \mathrm{~K}$ heat shield circuit of the accelerator, suggesting that the phenomenon was due to redistribution of adsorbed hydrogen in the thermal transition regions.

\section{RESULTS}

To date, we have applied helium-rf processing at $2 \mathrm{~K}$ to 90 cavities in 12 of the 41 installed CEBAF cryomodules. We have also applied pulsed-rf processing to condition the input waveguide region in 10 cryomodules. 


\subsection{Reduced radiation production}

Progress against field emission was observed by the reduction of $\mathrm{x}$-radiation produced by the field-emitted electrons. Figure 1 illustrates this shift as measured by the G-M tubes outside the cryomodule.

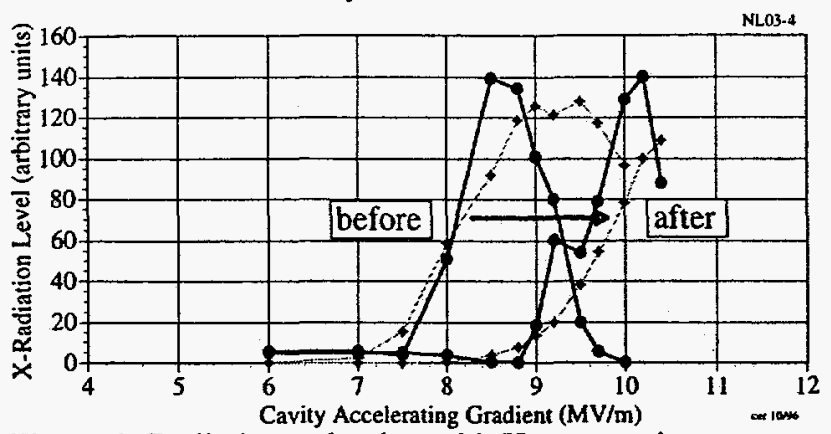

Figure 1. Radiation reduction with He processing.

\subsection{Reduced arcing and higher gradients}

Many of the cavities subjected to helium processing were previously limited by arcing at the cold window. Following processing, the cavities could be operated stably at higher gradients. Figure 2 shows the distribution of maximum gradients for the processed cavities according to their performance-limiting constraint.

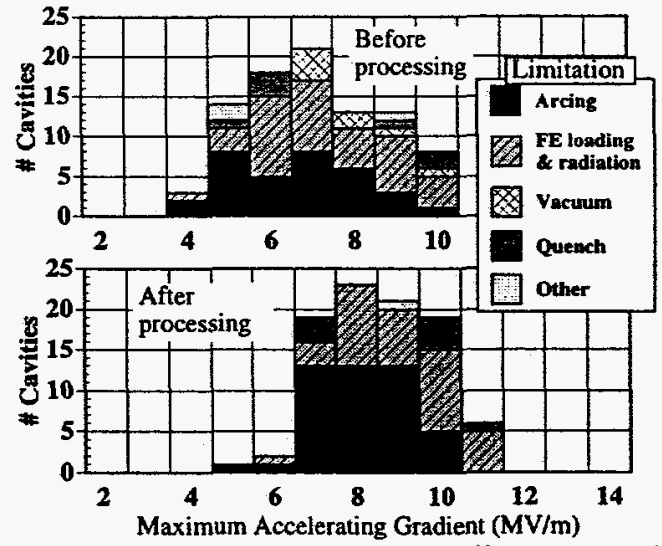

Figure 2. Cavity improvements with helium processing.

During the last year, we have recalibrated the cavity accelerating gradients based on actual beam acceleration. Following this, the helium processing effort also permitted us to reestablish the operational limits for some cavities.

\section{3 $\mathrm{Q}$ improvements}

Careful measurements were made of the unloaded $Q$-factor for cavities in the first cryomodule processed. All FElimited cavities showed improvement.

\begin{tabular}{|c|c|c|c|}
\hline $\begin{array}{c}\text { Cavity \# in } \\
\text { NL03 }\end{array}$ & \multirow{2}{*}{$\begin{array}{c}E_{\text {acc }} \\
(\mathrm{MV} / \mathrm{m})\end{array}$} & \multicolumn{2}{|c|}{$Q_{0}\left(\times 10^{9}\right)$} \\
\cline { 3 - 4 } & & Before & After \\
\hline 2 & 7.7 & 1.5 & 3.3 \\
\hline 4 & 8.7 & 2.5 & 4.1 \\
\hline 6 & 6.8 & 2.1 & $>5.3$ \\
\hline 8 & 8.8 & 2.85 & 4.7 \\
\hline
\end{tabular}

\subsection{Waveguide vacuum processing}

The waveguide vacuum in 10 cryomodules was conditioned by applying low duty cycle if pulses to each cavity, first detuned, and then tuned. The forward power was gradually increased to $4-5 \mathrm{~kW}$, subject to maintaining the waveguide vacuum better than $1 \times 10^{-7}$ torr. The process requires $\sim 4$ hours. In many cases, the vacuum stability improved markedly. This stability reduces a complication that arises when a cavity is slightly mistuned. The relative merits of this compared with a thermal cycle to $20 \mathrm{~K}$ or higher remain an open question.

\section{SUMMARY AND PROSPECTS}

Helium processing and requalification of cavities have increased the installed CEBAF voltage by $63 \mathrm{MV}$, corresponding to an added $315 \mathrm{MeV}$ for 5-pass beam. This improvement made possible the $1.12 \mathrm{GeV}$ single-pass test run completed in April 1997. At this rate we project an additional $135 \mathrm{MV}$ gain from processing the balance of the machine, which could be adequate for extending the energy reach of CEBAF to $6 \mathrm{GeV}$. Figure 3 presents the present voltage capacities of the CEBAF cryomodules.

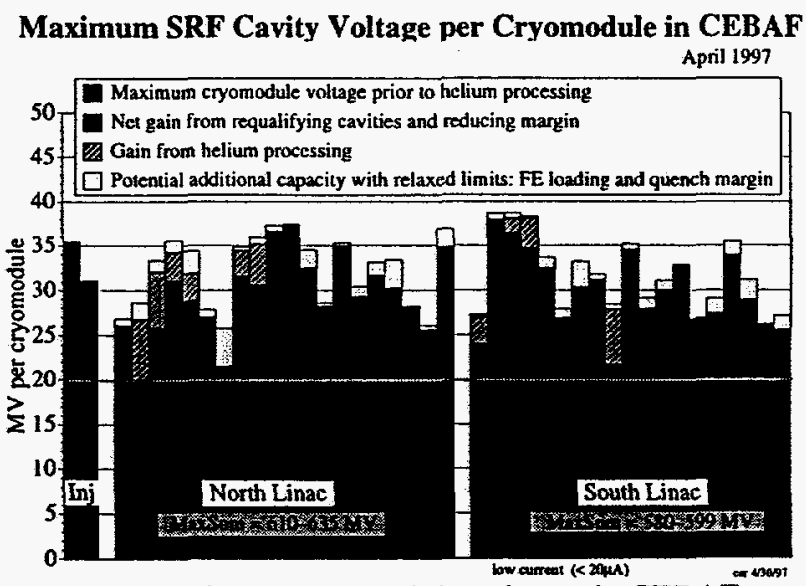

Figure 3. Maximum cryomodule voltages in CEBAF

\section{ACKNOWLEDGMENTS}

During processing, we received valuable assistance from L. Phillips, T. Powers, J. Mammosser, J. Brawley, K. Ryan, A. Lapolla, L. Harwood, G. Marble, F. Humphrey Jr., J. Heckman, K. Macha, J. Preble, and R. Bennett.

\section{REFERENCES}

[1] Work supported by the U.S. Department of Energy, contract DEAC05-84ER40150.

[2] 'Operation of CEBAF with Heavy Beam Loading', A. Hutton, these proceedings.

[3] 'Evidence for surface-state-enhanced field emission in if superconducting cavities', H. A. Schwettman, J. P. Turneaure, and R. F. Waites, J. Appl. Phys., 45, (1974) 914.

[4] 'Microscopic Investigation of Field Emitters Located by Thermometry in $1.5 \mathrm{GHz}$ Superconducting Niobium Cavities', $\mathrm{J}$. Knobloch and H. Padamsee, Particle Accelerators, 53, (1996) 53.

[5] 'Electronic Activity at CEBAF Cold RF Window Induced by Cavity Operation', V. Nguyen-Tuong, N. Luo, L. Phillips, C. Reece, EPAC 94 Proceedings, Volume 3, pp. 2200-2202. 